\title{
IMPERADORES DA INFORMAÇÃO: PODER E CENSURA NA INTERNET
}

Bárbara Nascimento ${ }^{1}$

NASCIMENTO, B. Imperadores da informação: poder e censura na internet. Rev. Ciênc. Juríd. Soc. UNIPAR. Umuarama. v. 17, n. 2, p. 185-203, jul./dez. 2014.

RESUMO: O objetivo da presente pesquisa é analisar até que ponto, dada a estrutura descentralizada e em rede da internet, é possível falar que ela possui agentes capazes de controlar a circulação da informação nela. Pretende-se demonstrar que a rede mundial de computadores não é livre de donos e que seus proprietários são aqueles que possuem poder de ingerência sobre o funcionamento físico do sistema ou sobre o fluxo de dados. No mundo atual, eles seriam a Apple, a Amazon, o Facebook, o Google, a Microsoft e os operadores de backbone.

PALAVRAS-CHAVE: Marco civil da internet; Agentes silenciadores; Restrição ao Direito Fundamental de Liberdade de Expressão.

\section{INTRODUÇÃO}

O que acontece se um provedor de acesso bloquear determinados sites sem que isso seja explicitado aos seus usuários ou se um mecanismo de busca que todos acreditam que seja neutro, começar a retornar resultados direcionados?

Afirma-se com frequência que a internet é livre de entidades controladoras. Em que pese isso ser verdade com relação à estrutura ideal da rede, pois diferentemente das mídias tradicionais, como a imprensa ou a televisão, a internet não possui um ponto central de controle da informação, a prática não equivale à teoria.

O objetivo da presente pesquisa é analisar até que ponto, dada a estrutura descentralizada e em rede da internet, é possível falar que ela possui agentes capazes de controlar a circulação da informação nela. Pretende-se demonstrar que a rede mundial de computadores não é livre de donos e que seus proprietários são aqueles que possuem poder de ingerência sobre o funcionamento físico do sistema ou sobre o fluxo de dados. No mundo atual, eles seriam a Apple, a Amazon, o Facebook, o Google, a Microsoft e os operadores de backbone.

O problema que advém dessa constatação é que a posição desses agentes dará, a cada um deles, a capacidade de censurar a rede, em maior ou menor

${ }^{1}$ Mestre em Teoria e Filosofia do Direito pela UERJ. Promotora de Justiça Substituta do MPRJ. 
medida, podendo configurar uma violação ao direito de acesso à internet.

Não se pretende ponderar, caso a caso, quando o direito à liberdade de expressão do particular ou seu direito de acesso à internet preponderariam em detrimento da liberdade do agente privado. Ou seja, não se pretende analisar se pais podem censurar a internet de filhos, empresas de empregados ou escolas de alunos, por exemplo, mas sim analisar o poder de censura daqueles que dominam a rede em si.

Também não se pretende discutir, neste momento, os recursos que os governos podem utilizar para censurar a internet: o foco é em agentes econômicos privados.

Além disso, como afirma Jorge Reis Novais, no mundo dos direitos fundamentais, a explicitação do conflito é o primeiro pressuposto para a realização de uma ponderação constitucionalmente adequada. Em outras palavras, o conflito de interesses deve ser exposto da forma mais transparente possível para que o intérprete e aplicador da lei possa solucionar casos difíceis pela ponderação, de forma intersubjetivamente controlável segundo os princípios constitucionais (NOVAIS, 2006).

Por fim, parte-se da premissa de que tanto a censura pelo hardware como a censura pelo software podem levar ou ao bloqueio de conteúdos específicos na internet ou ao bloqueio do acesso à internet como um todo.

\section{PREMISSAS JURÍDICAS}

A Lei 12.965/2014, o chamado Marco Civil da Internet, em seus artigos $4^{\circ}, \mathrm{I}$, e $8^{\circ}$, positivou expressamente no ordenamento brasileiro o direito de acesso à internet. ${ }^{2}$ Defende-se que o conteúdo de tal direito inclui duas dimensões: o acesso à infraestrutura física necessária à conexão e o acesso ao conteúdo disponível na rede.

Esse direito de acesso à internet está diretamente ligado à liberdade de expressão, como reconhecido pelo referido artigo $8^{03}$. Entende-se tradicionalmente que a liberdade de expressão é um direito que enseja prestações negativas do Estado. Ou seja, a vedação à censura dirige-se, em regra, ao poder público, o qual deve abster-se de interferir nas manifestações lícitas dos indivíduos (MENDES, 2008).

Contudo, atualmente, não se nega a possibilidade de ser reconhecida a

${ }^{2}$ Defendo, em obra específica (NASCIMENTO, Bárbara Luiza Coutinho do. O Direito Humano de Acesso à Internet: fundamentos, conteúdo e exigibilidade. Amazon, Ebook Kindle, 2013.), que esse direito deve receber o status de direito humano, pelos fundamentos lá apresentados. Para o estudo desenvolvido no presente artigo, contudo, essa questão não será tratada.

${ }^{3}$ Art. 8o - A garantia do direito à privacidade e à liberdade de expressão nas comunicações é condição para o pleno exercício do direito de acesso à internet. 
eficácia horizontal da liberdade de expressão. E essa possibilidade cresce à medida que o uso da internet cresce. Explica-se: na internet, não é o Estado que tem se mostrado o principal agente silenciador das manifestações de pensamento, mas sim os agentes privados. A voz que o cidadão tem na internet é uma voz, em regra, mediada. Mediada pelo seu aparelho de comunicação (desktop, notebook, tablet, aparelho celular, videogame, televisão, roteador, etc.), pelo seu serviço de acesso à internet e pelos serviços virtuais que o indivíduo usa para expor uma ideia (Facebook, Twitter, blog, o servidor no qual ele hospeda seu próprio site, etc.), dentre outros. Todos esses são, em regra, produtos ou serviços oferecidos por agentes privados.

Apenas para exemplificar, o indivíduo pode utilizar um MacBook e se conectar à internet pelo provedor Net Vírtua para utilizar o Twitter e expor suas ideias para o mundo virtual. Todos esses agentes privados citados possuem, cada qual, o poder de censurar aspectos da liberdade de expressão desse indivíduo, como será demonstrado adiante. Mas o que é importante ressaltar neste ponto é que, como em qualquer incidência de direitos fundamentais em relações privadas, os interesses envolvidos nesses casos também precisarão ser ponderados quando se tratar de eficácia horizontal da liberdade de expressão.

Assim, saber qual é o limite da liberdade individual na internet dependerá do caso concreto. Não é o objetivo desta pesquisa, repita-se, ponderar cada caso, mas sim desmistificar a crença de que a internet não tem agentes controladores. Pelo contrário, ela tem e eles são capazes de realizar uma censura em larga escala desse meio de comunicação. A partir do momento em que esse potencial de censura é revelado, fica claro que esses agentes são capazes de violar o direito de acesso à internet do indivíduo e essa informação passa a integrar a ponderação.

\section{DONOS DO CONTEÚDO E CENSURA PELO SOFTWARE}

Apesar de a internet ser composta por incontáveis websites, poucos controlam a maior parte do fluxo da rede, constituindo verdadeiros nódulos centrais, essenciais para o fluxo de dados online (GUADAMUZ, 2011, p. 76). Em 8 de outubro de 2012, o site Alexa ${ }^{4}$, que faz constantes medições, indicava que o Google era o site mais visitado do mundo, seguido pelo Facebook, Youtube, Yahoo!, Baidu, Wikipédia, Windows live, Twiter, qq.com e Amazon, todos originalmente norte-americanos, à exceção do Baidu e do qq.com, que são chineses.

Vania Baldi, atento para a questão do controle do fluxo da informação na rede, afirma que a internet possui quatro "proprietários": Amazon, Apple, Facebook e Google (BALDI, s.a). A razão pela qual ele indica esses agentes é

${ }^{4}$ Estatística disponível em: <http://www.alexa.com/topsites>. Acesso em 8 out. 2012. 
facilmente identificável.

O Facebook é, atualmente, a rede social dominante. Em 14 de setembro de 2012, ele informou ter alcançado a marca de 1 bilhão de usuários ativos no mês (FOWLER, 2012). Apesar da empresa estar enfrentando dificuldades para provar a seus investidores que é capaz de gerar lucro (SCHNEIDER, 2002), talvez o verdadeiro poder do Facebook resida no fato de ele ser um grande arquivo de fichas pessoais, com fotos, vídeos, comentários públicos, trocas de mensagens privadas, divulgação de preferências individuais, etc. É por essa razão que Evgeny Morozov afirma que databases são melhores do que oficiais da Stasi para adquirir informações sobre as pessoas (MOROZOV, 2011).

O Google revolucionou a forma como pesquisas são feitas na internet. Sua interface simples e o visual limpo facilitaram a busca para usuários inexperientes. Além disso, o site não aceitava dinheiro para promover alguns links à frente de outros (VAIDHYANATHAN, s.a): originalmente, a ordem dos resultados era determinada pela popularidade deles. O sucesso pode ser facilmente visto nos números: em 2009 ele já processava mais de 1 bilhão de pedidos de busca todos os dias (KUHN, 2012) e no período de setembro de 2011 a setembro de 2012, foi responsável por $91,4 \%$ do mercado de buscas na internet ${ }^{5}$.

Note-se que sem os mecanismos de busca, a internet perderia muito de seu potencial. Sem a indexação que eles promovem, seria muito difícil encontrar uma informação específica no meio de todas as páginas da rede.

A Amazon é a principal loja virtual. Se a internet fosse um shopping, ela seria a loja âncora. Uma pesquisa divulgada no ano de 2012 estimou que $30 \%$ de todos os compradores online começam suas buscas pelo site, que ele é responsável por $19 \%$ da renda do ecommerce norte-americano e que $86 \%$ dos norte-americanos que já compraram algo online, compraram na Amazon (DAVIS, 2012).

Já a Apple se apresenta como um caso único. Ela controla uma significativa parte do mercado de hardware e se vale desse fato para controlar também o mercado de software, não dando ao usuário muita liberdade para optar por aplicativos de outros desenvolvedores. Os sistemas operacionais desenvolvidos pela Apple apenas funcionam em computadores da Macintosh e são os únicos que funcionam neles, sendo que o mesmo é válido para os celulares e tablets. É como se o usuário comprasse um aparelho de DVD que apenas pudesse ler discos do próprio fabricante do aparelho e esses discos não pudessem ser lidos em aparelhos de outros fabricantes.

Devido ao enorme sucesso conquistado por aparelhos como o iPod, iPad, iPhone e MacBook, em março de 2010, ela superou a Microsoft e passou a ser a maior companhia de tecnologia no mundo, avaliada em mais de 240 bilhões

${ }^{5}$ Estatística disponível em: $<$ http://gs.statcounter.com/\#search_engine-ww-monthly-201109-201209bar>. Acesso em 5 out. 2012. 
de dólares (WU, 2011).

Mas em que pese a afirmação de Baldi ser pertinente, ela se limita aos proprietários do conteúdo virtual da rede, com exceção da Apple. A essa categoria podem ser agregadas outras duas: os proprietários da estrutura física, que são os mais fortes agentes desse mercado e serão estudados no próximo tópico, e os proprietários dos sistemas operacionais. Isso porque o controle do sistema operacional significa o controle do código e, nas palavras de Lessig (2010), na internet o código é a lei. ${ }^{6}$

Nesse último quesito, a Microsoft permanece imbatível. As estatísticas indicam que mais de $80 \%$ dos computadores utilizam um Sistema Operacional da família Windows? ${ }^{7}$.

Mas por que o controle do código é tão importante? Por que o sistema operacional é uma arma nessa guerra? Porque é o código que determina a língua que o usuário utiliza para falar com a internet e, dessa forma, as possibilidades de uso dos diversos outros softwares. Em outras palavras, algo que um sistema operacional não permita, um software não faz.

A dominação do mercado da Microsoft é diretamente responsável pela inclusão digital, pois foi a sua interface gráfica intuitiva que permitiu que usuários sem qualquer conhecimento técnico pudessem usar computadores. A família Windows, em especial após o Windows 95, facilitou a comunicação do usuário com a máquina. Diante dessa dominação do código, hardwares e softwares passaram a ser desenvolvidos para que fossem compatíveis com a família Windows, usuários e profissionais foram treinados em ambiente Windows e qualquer novo sistema operacional lançado pela Microsoft é facilmente difundido.

Se a Microsoft simplesmente saísse de cena, deixaria um buraco que não poderia ser substituído por outras companhias em curto prazo. E atualmente o sistema operacional está tão integrado à internet que a Microsoft, ao disponibilizar o Windows, já oferece ao usuário toda uma teia de serviços online.

Assim, ela aproveita a sua dominação do mercado de sistema operacional para dominar aspectos da internet que possam ser integrados a ele. A empresa, ao lançar o sistema operacional Windows 8, em 25 de outubro de $2012^{8}$, apresentou como uma das principais características prometidas para o novo sistema a total integração dele a seus serviços online, como o Microsoft SkyDrive, um disco virtual para armazenamento e compartilhamento de arquivos, e o Xbox Live, sistema utilizado pelo Xbox360, o principal videogame da empresa, res-

${ }^{6}$ LESSIG, Lawrence. Code 2.0.Soho Books, 2010. p. 5.

${ }^{7}$ Estatísticas disponíveis em: $<$ http://www.w3schools.com/browsers/browsers_os.asp $>$. Acesso em 5 out. 2012.

${ }^{8}$ Windows 8 será lançado dia 25 de outubro. Disponível em: <http://tecnologia.uol.com.br/noticias/ redacao/2012/09/17/microsoft-oficializa-data-de-lancamento-do-windows-8.htm>. Acesso em 6 out. 2012 . 
ponsável por quase $39,6 \%$ do mercado global de consoles, equivalente a mais de 68 milhões de unidades vendidas até 7/10/2012 ${ }^{9}$. Além disso, a empresa desenvolveu total integração entre seu novo navegador, o Internet Explorer10, e o Windows 8. Em janeiro de 2013 a Microsoft anunciou que o sistema operacional recém-lançado já havia vendido 60 milhões de cópias (DESTRO, 2013).

Mas foi ao ser lançado para o sistema anterior, o Windows7, que o Internet Explorer10 dobrou seus usuários (BRIGHT, 2013). Não se pode perder de vista que apesar de já ter perdido espaço, o Internet Explorer, em suas múltiplas versões, permanece, por algumas medições, o navegador mais utilizado no mundo e, por outras, o segundo mais utilizado ${ }^{10}$. E é basicamente o navegador que determina os recursos disponíveis para os programadores de sites. Em outras palavras, se um webmaster desenvolve um site que não é compatível com o Explorer, perderá muitos visitantes. Também não se deve desconsiderar que o Windows Live, de acordo com a pesquisa supracitada, está entre os sites mais visitados do mundo.

O poder de fato da Microsoft é tão evidente que ela já foi condenada por violar dispositivos do Sherman Act no caso United States v. Microsoft ${ }^{11}$. Ela também foi acusada pela União Europeia de constituir monopólio. ${ }^{12}$

Mas o certo é que todos esses agentes citados por Baldi, ou seja, Amazon, Apple, Facebook e Google, assim como a Microsoft, possuem o poder de, em alguma medida, censurar o usuário.

A Apple é duramente criticada por seus sistemas operacionais apresentarem o código fechado em um nível que o computador pessoal nunca apresentou. Alegam os críticos que os sistemas da Apple são desenvolvidos para fomentar o consumo, e não a criação. A empresa permite que terceiros desenvolvam aplicativos, mas de forma restrita: é ela que decide quais programas poderão ou não rodar no iPad e no iPhone (WU, 2011).

Os standards para essa decisão são, contudo, obscuros. Ela apresenta uma lista de razões, muitas delas com conteúdos subjetivos, para rejeitar aplicativos. A título de exemplo, uma dessas razões diz que a Apple pode recusar aplicativos cujo conteúdo ou comportamento ela acredite estar "além do limite", sem especificar de qual limite se trata (Id. Ibid.).

Frequentemente, conteúdos políticos e religiosos controvertidos são

\footnotetext{
${ }^{9}$ Estatísticas disponíveis em $<\mathrm{http}: / /$ www.vgchartz.com>. Acesso em 7 out. 2012.

${ }^{10}$ Estatísticas disponíveis em $<$ http://gs.statcounter.com $>$ e em $<$ http://www.w3 counter.com/globalstats.php>.

${ }^{11}$ United States v. Microsoft Corporation. Antitrust case filings. The United States Department of Justice.Disponível em: <http://www.justice.gov/atr/cases/ms index.htm>. Acesso em 7 out. 2012.

${ }^{12}$ Acusada de monopólio, Microsoft libera código de principais softwares. Disponível em: $<\mathrm{http} / /$ g1.globo.com/Noticias/Tecnologia/0,,MUL308641-6174,00-ACUSADA+DE+MONOPOLIO+MI CROSOFT+LIBERA+CODIGO+DE+PRINCIPAIS+SOFTWARES.html>. Acesso em 7 out. 2012.
} 
censurados, assim como charges que, segundo a empresa, ridicularizam figuras públicas (MACKINNON, 2012), desconsiderando que o papel da charge é, muitas vezes, desconstruir a imagem de uma figura pública para reconstruí-la de forma cômica, porém crítica.

Por exemplo, o aplicativo para iPad de uma das maiores revistas alemães, Stern, foi sumariamente retirado do ar pela Apple por publicar um conteúdo erótico na revista impressa que foi, junto com todo o conteúdo da revista, disponibilizado em formato digital pelo aplicativo. O fato de o conteúdo ser permitido na Alemanha não foi considerado. A empresa também ordenou à outra revista alemã, a Bildt, que alterasse seu conteúdo caso quisesse continuar com seu aplicativo (WU, 2011). Resumidamente, a Apple utiliza seu controle sobre o hardware para controlar o que o indivíduo pode ou não fazer com ele após a venda do produto.

Além disso, o Skype e o Google Voice, dois aplicativos para realizar chamadas pela internet de graça, inicialmente sofreram bloqueio da Apple, por contrariar os interesses de sua parceira comercial, a AT\&T. A Apple fundamenta seu poder de veto no direito que uma loja tem de não estocar produtos que não queira, e apenas retirou os bloqueios após a interferência da Federal Communications Commission (FCC) (WU, 2011).

Aqueles que criticam a empresa, como Tom Conlon da revista Popular Science, alegam que o próximo passo seria ela bloquear filmes, programas de TV, músicas, livros e sites (id. Ibid.). Com base nisso, Tim Wu afirma que todos sabem o quão user-friendly a interface da Apple é, mas poucos percebem o quão Hollywood-friendly ela é ao proteger os interesses da indústria de filmes (WU, 2011).

Talvez a razão de o controle de um sistema operacional ser tão importante fique mais clara de ser visualizada no caso da Apple do que no caso da Microsoft. E o motivo é simples: a Apple se vale desse poder mais do que a Microsoft, mas isso não significa que a Microsoft não possa fazer o mesmo se quiser.

Mas o domínio da Apple não permaneceu sem rivais por muito tempo. Em 5 de novembro de 2007, o Google anunciou o lançamento do Android, um sistema operacional para celulares de código aberto, apto a ser utilizado por qualquer fabricante do aparelho. No início de 2011, ele já havia superado a venda de smartphones da Apple. Não se deve ser ingênuo de acreditar que o Google não tem pretensões de, ao rivalizar com a Apple, tornar o ambiente dos smartphones mais adaptado aos seus serviços e de seus parceiros comerciais, mas o sucesso do Android apenas reforça a ideia de que sistemas abertos sempre ganham. É por isso que o ex-CEO do Google, Eric Schmidt, afirmou que "o usuário final prefere escolha, liberdade e abertura" (WU, 2011, p. 294-299).

Contudo, o Google também não permanece imune à críticas. Ele e o 
Facebook destacam-se no grupo dos proprietários da internet por serem as duas empresas integralmente virtuais. Como foi dito, originalmente o Google indicava os resultados das buscas com base na popularidade dos sites, de forma neutra. Isso mudou em 4 de dezembro de 2009, quando ele anunciou a "busca personalizada" (PARISER, 2011, p. 1).

Pelo novo sistema, o site utiliza sinais, considerando elementos como o local do qual a pessoa está se conectando, o browser que ela está usando e o que ela pesquisou previamente, para apresentar resultados baseados na preferência do usuário. Dessa forma, duas pessoas diferentes buscando o mesmo termo encontram resultados diferentes (Id. Ibid.). Com isso, a prometida política de neutralidade do Google se desfez.

A empresa promete manter a privacidade do usuário e os dados indicam que até agora ela tem cumprido essa promessa, mas seu objetivo é simples: quanto mais personalizada for a experiência, mais adequados ao perfil do comprador serão os anúncios oferecidos, assim mais provável será que ele clique nesses anúncios e compre os produtos ofertados. Essa estratégia é usada não apenas pelo Google como também pela Amazon, pelo Facebook, pelo Yahoo, pelo Youtube e pelo Microsoft Live, todos sites com elevado número de visitantes (Id. Ibid. p. 7-8). Essa conduta, contudo, não é explicitada para o usuário e permanece fora do conhecimento da maior parte das pessoas. Além disso, muitas vezes não é dada a elas a opção de recusar a personalização e realizar uma busca neutra.

A vantagem desse método é que ele permite ao usuário encontrar as informações específicas desejadas dentro do mar de informações que a internet se tornou; o problema desse método é o que a internet não mostra: ao personalizar a busca de acordo com aquilo que o usuário já sabe, perde-se o grande benefício que a internet oferece, que é a descoberta do diferente. Troca-se o fomento do dissenso, tão caro à democracia e à política dos Direitos Humanos, pelo consenso, formador de massas acríticas.

Ressalte-se que nada impede que os referidos agentes utilizem esse método para direcionar a experiência do usuário de acordo com sua própria preferência política ou ideológica, excluindo dos resultados sites, vídeos ou manifestações contrárias aos interesses da empresa. E, como dito, não é porque hoje esses agentes não fazem isso que eles não possam fazer no futuro.

\section{DONOS DA ESTRUTURA FÍSICA E CENSURA PELO HARDWARE}

É possível falar em censura física do mundo virtual? Sim, e trata-se da mais poderosa. Em que pese o domínio do conteúdo que circula na internet ser importante, ele não se compara ao poder advindo do domínio da estrutura física da rede. O CEO da AT\&T, Ed Whitacre, ao ser perguntado em uma entrevista 
sobre o quanto se preocupava com os pretensiosos da internet, como Google, MSN e Vonage, respondeu: "como você acha que eles alcançarão os consumidores? Por um tubo de banda larga." E complementou: "Companhias de cabos os têm. Nós os temos. Eles gostariam de usar meus tubos de graça, mas eu não irei deixá-los" (WU, 2011, p. 284-285).

Para aprofundar a análise do presente tópico, inicialmente é necessário apresentar uma resumida explicação de como a internet funciona:

Quanto à sua estrutura, a Internet pode ser definida como uma rede mundial de computadores composta por redes menores, ou seja, como uma rede de redes. (...) Assim, quando o usuário se conecta ao seu provedor de internet, forma com ele uma rede. O provedor, por sua vez, se conecta a outro provedor maior, nacional ou internacional, formando com ele outra rede. Os grandes provedores fornecem a estrutura física da internet, de cabos e roteadores, chamada de internet backbone. Todos os provedores que estão no topo dessa hierarquia de redes se conectam, então, a Pontos de Troca de Tráfego, ou PTTs, que são comutadores ou redes centrais que viabilizam a troca de dados entre as redes diretamente conectadas ao PTT e, consequentemente, entre todos os computadores conectados à qualquer das redes interconectadas (NASCIMENTO, 2011).

Estima-se que no ano 2000 existiam em todo o mundo apenas 5 operadores no topo da hierarquia da rede física descrita, classificados como tier $1^{13}$. São eles: Cable \& Wireless Worldwide, UUNet, Sprint, AT\&T e Genuity, todas norte-americanas (ROSEMAN, 2003, p. 25-27). Em janeiro de 2011 estima-se que eram 13, sendo 7 norte-americanas, uma alemã, uma italiana, uma sueca, uma japonesa, uma espanhola e uma indiana. ${ }^{14} \mathrm{Assim}$, se um desses poucos operadores de backbone parar de funcionar, grande parte da rede perderá a habilidade de se comunicar.

Note-se que apesar de haver divergência sobre o quanto uma única instalação pode ser importante para o funcionamento da internet, já que a rede é redundante, com alguns estudiosos defendendo que os links facilmente contornariam o buraco deixado utilizando rotas alternativas e outros afirmando que alguns setores da rede poderiam ter sua conexão interrompida ou sofrer uma queda brutal de velocidade e estabilidade (BLUM, 2012, p. 115), o fato é que problemas nos cabos submarinos afetam milhões de usuários todos os anos.

\footnotetext{
${ }^{13}$ Redes Tier 1 são aquelas que podem alcançar todas as redes conectadas à internet sem precisar pagar a outras redes por tráfego. (BERG, Rudolph van der. How the 'Net works: an introduction to peering and transit.Disponível em: $<$ http://arstechnica.com/guides/other/peering-and-transit.ars/4>. Acesso em 4 out. 2012.)

${ }^{14}$ Estatísticas disponíveis em $<$ http://as-rank.caida.org> . Acesso em 4 out. 2012.
} 
Em janeiro e fevereiro de 2008, danos a cabos submarinos no Mar Mediterrâneo causaram transtornos a 70\% da rede do Egito, prejudicando 6 milhões de usuários, a $60 \%$ da rede da Índia, atingindo 60 milhões de usuários, e problemas nos Emirados Árabes Unidos, onde 1 milhão e 700 mil usuários foram prejudicados, Paquistão, onde 12 milhões de usuários foram afetados, Arábia Saudita, atingindo 4 milhões e 700 mil usuários, além de afetar usuários no Afeganistão, Bahrein, Bangladesh, Kuwait, Maldivas, Catar, e Sri Lanka. A maior parte dos serviços foi restaurada após 24 horas (ZAIN, 2012).

Em fevereiro de 2012, um corte em um cabo submarino no leste africano demorou mais de 3 semanas para ser reparado, gerando intermitência e redução da velocidade das conexões no Quênia, Etiópia, Ruanda, Burundi, Uganda, Tanzânia, Sudão do Sul, Zâmbia e Zimbábue (KABWEZA, 2012).

Em junho de 2012, o corte de um cabo próximo a Singapura interrompeu o acesso à internet de milhões de usuários de Bangladesh e reduziu drasticamente a velocidade dos que conseguiram permanecer conectados. Usuários privados, empresas e setores governamentais foram afetados. O país não possuía uma rota alternativa. ${ }^{15}$

Em 27 de agosto de 2012 foi a vez do Reino Unido sofrer. O corte de um cabo que ligava Blighty à Holanda fez com que algumas regiões da internet ficassem inacessíveis para os usuários da $\mathrm{O} 2$, uma importante empresa de telecomunicação britânica, e sites como o do popular jogo onlineWorld of Warcraft, da BBC, da Amazon e do Facebook ficaram indisponíveis por mais de 24 horas (FIVEASH, 2012).

Rompimentos de cabos submarinos geralmente são gerados por terremotos, atrito com o solo marinho ou âncoras de navios.

Fora do mar, na Geórgia, em março de 2011, uma senhora de 75 anos derrubou a conexão de toda a Armênia por cerca de 5 horas quando, ao cavar procurando por cobre, danificou o cabo que conectava os dois países. Ela ganhou o apelido de spadehacker por esse evento. A Geórgia era responsável por prover, à época, 90\% da internet da Armênia (PARFITT, 2012).

Retomando a questão do domínio da estrutura física da rede por poucas empresas, a título de exemplo, a instalação conhecida como NAP of the Americas, de propriedade da empresa privada Terremark, uma subsidiária da Verizon localizada em Miami, é responsável por cerca de $95 \%$ de todo o tráfego de dados da internet entre a América do Norte e a América Latina (LONG ROAD FROM CUBA, 2012). A mesma empresa é proprietária da instalação NAP do Brasil, em São Paulo, e afirma que se trata do mais importante ponto de troca de tráfego da América Latina (TERREMARK, 2012).

\footnotetext{
${ }^{15}$ Bangladesh Internet down after submarine cable cut.Disponível em: $<$ http://www.channelnewsasia. com/stories/afp_asiapacific/view/1206158/1/.html>. Acesso em 4 out. 2012.
} 
É verdade que novos agentes estão ingressando no mercado, mas o que importa discutir no presente ponto é que tais agentes, que operam o backbone da internet, são poucos e em sua maioria privados, e bastaria que um desses agentes cortasse o serviço para que, como demonstrado, alguns usuários ou até mesmo países inteiros ficassem com a conexão muito lenta ou interrompida. Em outras palavras, ninguém é dono da internet mais do que os operadores de backbone. Compreender a capacidade latente deles de derrubar o sistema ou controlar o fluxo de dados é fundamental para a compreensão da distribuição de poder sobre a internet.

Reconhecendo isso, os norte-americanos, de executivos da indústria a oficiais de inteligência da C.I.A., seja por questões econômicas ou estratégicas, mostraram preocupação com a perda de importância do país no controle do fluxo de dados da rede, já que os novos operadores de backbone que estão surgindo são de outros países. Foi o fluxo significativo de dados pelos EUA que permitiu que a C.I.A. rastreasse inúmeros terroristas nos últimos anos (MARKOFF, 2012). ${ }^{16}$

Apesar de ser óbvio, não é demais explicitar que além de poder interromper a conexão dos usuários com a rede, o que configura censura e viola o direito de acesso à internet, o fato de os operadores de backbone controlarem os cabos pelos quais os dados circulam permite que eles controlem os dados em si, se desejarem. ${ }^{17}$

Além de poder ser fisicamente controlada no topo da hierarquia da rede, a internet também pode ser censurada no aparelho pessoal que o usuário final usa para se conectar. Como já tratado, cada vez mais os fabricantes de hardware buscam controlar o comportamento online do usuário após a venda e entrega do produto.

Em 28 de agosto de 2012 a Apple patenteou uma tecnologia chamada "aparatos e métodos para coação de políticas sobre um dispositivo wireless" (BELL, et al., 2012) que permite desabilitar à distância os telefones celulares de sua fabricação (iPhones) ou recursos específicos nesses aparelhos, como as câmeras fotográficas, quando o usuário entrar em uma determinada localização ge-

\footnotetext{
${ }^{16}$ Recentemente, contudo, os EUA têm adotado medidas, com fundamento no Patriot Act, no Stored Communications Act e em outras leis, que permitem que os oficiais do governo possam juridicamente obrigar as empresas sediadas nos EUA a fornecerem dados que não estejam geograficamente hospedados nos EUA, mas que estejam hospedados em servidores internacionais de propriedade dessas empresas norte-americanas, em especial a Microsoft e o Google. Para aprofundar a questão, vide: WHITTAKER, Zack. Yes, the FBI and CIA can read your email. Here's how. Disponível em: $<$ http://www.zdnet.com/yes-the-fbi-and-cia-can-read-youremail-heres-how-7000007319>. Acesso em: 7 abr. 2013. LARDNER, Richard. Not that hard for authorities toget to your email. Disponível em: $<$ http://finance.yahoo.com/news/not-hard-authorities-email-131531468.html $>$. Acesso em: 7 abr. 2013.

${ }^{17}$ Para uma explicação técnica de como isso é possível, vide DEIBERT, Ronald et al. Access Denied: the practice and policy of globalinternet filtering. Cambridge, Massachusetts: The MIT Press, 2008.
} 
ográfica. A "política" da zona, que determinará quais funções do aparelho serão habilitadas ou desabilitadas, poderia ser determinada por Governos, negócios, ou operadores de rede, por exemplo.

Alega a fabricante que em determinados locais, como cinemas, hospitais ou em reuniões, o toque ou a luminosidade excessiva dos aparelhos pode incomodar outras pessoas. Em outros locais pode não ser permitido tirar fotos e em outros, como aeroportos, o funcionamento do aparelho pode causar riscos à segurança. Assim, ao entrar em uma dessas zonas, o aparelho celular da pessoa receberia um comando para reduzir a luminosidade, desligar o $\mathrm{Wi}-\mathrm{Fi}$, entrar em modo vibratório, modo "soneca" ou modo "avião", dentre outras alternativas.

Note-se que ao forçar o smartphone a entrar em modo "soneca" ou modo "avião" retira-se também a possibilidade de ele estabelecer uma conexão com a internet. Além disso, apesar de todos os recursos da tecnologia não serem descritos, parece que ela pode ser utilizada para bloquear pura e simplesmente a conexão de rede do aparelho, retirando a possibilidade de se conectar à internet por $W i-F i$ ou pelo próprio sistema de telefonia.

Em que pese reconhecer-se que em determinados locais, como presídios ou áreas específicas de aeroportos, o funcionamento de aparelhos wireless possa e deva ser bloqueado por questões de segurança, trata-se mais uma vez de uma questão de ponderação. É possível imaginar que empresas ou fábricas tenham interesse legítimo em bloquear o funcionamento de celulares ou das câmeras anexas, por exemplo, em áreas estratégicas. Mas em estabelecimentos abertos ao público, a situação é diferente. Assim, tem um cinema o direito de modificar a configuração do aparelho celular de uma pessoa à distância? A princípio, parece que não. Por mais incômodo que seja um celular tocar no meio de um filme, por mais que tal atitude viole regras de conduta social, não há ilícito, não há conduta contrária ao direito sendo realizada pelo particular. E ainda que houvesse, poderia o cinema, agente privado, forçar o cumprimento da lei a toda uma coletividade, interferindo no funcionamento da propriedade privada alheia? Coagir o indivíduo a se portar de acordo com uma lei que tutelasse um suposto direito a não ser incomodado no cinema? Proibir o uso de celular em uma sala de cinema é diferente de, sem o consentimento do indivíduo, alterar remotamente as configurações do aparelho.

E essa ponderação não deve ser deixada exclusivamente a cargo de agentes privados. Ao contrário, o ideal seria que existisse uma lei regulamentando-a. A proibição do uso de aparelhos celulares em bancos no Estado do Rio de Janeiro, por exemplo, veio por lei. Mesmo assim alguns a acusam de ser materialmente inconstitucional, por violar o direito de propriedade do indivíduo. ${ }^{18}$

\footnotetext{
${ }^{18} \mathrm{RJ}$ proíbe uso de celular nas agências bancárias. Disponível em: $<$ http://www.conjur.com.br/2011-abr-07/estado-rio-janeiro-proibe-uso-celular-agencias-bancarias>. Acesso em 9 out. 2012.
} 
É certo que nem todas as tecnologias patenteadas são, de fato, implementadas. Mas independentemente de vir a ser esta tecnologia implantada ou não, a patente indica em que tipo de tecnologia a Apple e possivelmente outros fabricantes de hardware ou desenvolvedores de software estão pesquisando para futuramente disponibilizar: aparelhos e/ou protocolos que consigam controlar outros aparelhos, limitando seus recursos ou sua capacidade de comunicação, incluindo a possibilidade de acesso à internet.

Os riscos que o mal uso de tal tecnologia pode trazer são evidentes. Governos poderiam utilizá-la para impedir manifestações populares lícitas.

A título de exemplo, em agosto de 2011, após alguns manifestantes se reunirem para protestar pacificamente em uma estação de metrô no centro da cidade de São Francisco, a polícia do BART ${ }^{19}$ ordenou a várias operadoras de telefonia celular que cortassem o serviço naquela área, impedindo o uso do aparelho mesmo em situações de emergência, sob o argumento de que a manifestação contrariava a lei e ameaçava a segurança dos passageiros ${ }^{20}$.

A manobra foi duramente questionada por especialistas em direitos civis e pela sociedade, gerando a reação do grupo hacker Anonymous, que afirmou que o "(...) Anonymous tentará mostrar àqueles engajados na censura, qual é a sensação de ser silenciado". ${ }^{21}$

Note-se que tal situação não ocorreu na China ou na Coréia do Norte, mas sim no centro da cidade de São Francisco, famosa por sua diversidade cultural e por ser um centro de ativismo liberal.

Mas a reação também veio do Estado. Especificamente em resposta a esse evento, em agosto de 2012 o Legislativo da Califórnia aprovou por unanimidade um projeto de lei que veda a interrupção de serviços de celular ou de internet wireless sem ordem judicial. Segundo o Senador Estadual Alex Padilla, já existiam leis que visavam a impedir exatamente esse tipo de ação, mas elas se limitavam ao serviço de telefonia tradicional. Portanto, uma atualização se mostrava necessária para impedir a interrupção do funcionamento de celulares ou de serviços de internet wireless sem ordem judicial (ADLER, 2012). A lei, contudo, foi vetada pelo Governador, que a devolveu ao Senado Estadual. O veto não foi apreciado. ${ }^{22}$

\footnotetext{
${ }^{19}$ BART significa Bay Area Rapid Transit. É um serviço de transporte sobre trilhos que conecta a área da Baía de São Francisco. O BART possui o seu próprio departamento de polícia.

${ }^{20}$ Police shut down San Francisco transit station after protests. Disponível em: $<$ http://www.msnbc. msn.com/id/44153343>. Acesso em: 9 out. 2012.

${ }^{21}$ Hacker group posts names of BART site subscribers. Disponível em: <http://www.msnbc.msn.com/ $\mathrm{id} / 44139412 / \mathrm{ns} /$ technology_and_science-security/t/hacker-group-posts-names-bart-site-subscribers>. Acesso em: 9 out. 2012.

${ }^{22}$ SB-1160 Communications: service interruptions. Disponível em: $<$ http://leginfo.legislature.ca.gov/ faces/billCompareClient.xhtml>. Acesso em: 12 abr. 2013.
} 
Essa explicação apenas reforça a crítica que fiz a Baldi, no sentido de que os maiores proprietários da internet são aqueles que controlam sua estrutura física. Se um site ou um software fica indisponível ou se mostra muito fechado ou controlador, quase sempre o usuário poderá optar por outros equivalentes. Quando é um operador do backbone que age assim, não restam muitas alternativas.

E nesse cenário em que os principais ofensores da liberdade de expressão são agentes privados, o papel histórico do Estado curiosamente se inverte, pois ele passa de violador a garantidor da liberdade de expressão em face dos demais particulares, exatamente como ocorreu no caso de São Francisco ${ }^{23}$, quando da proposição da lei.

É por essa razão que o jovem Marco Civil da Internet positivou dispositivos que tentam impedir tais condutas. Além do já mencionado direito de acesso à internet, outros exemplos podem ser citados. $\mathrm{O}$ art. $7^{\circ}$, IV, veda a suspensão da conexão com a internet, salvo por débito diretamente decorrente de sua utilização, e o art. $9^{\circ}, \S 3^{\circ}$, afirma que "na provisão de conexão à internet, onerosa ou gratuita, bem como na transmissão, comutação ou roteamento, é vedado bloquear, monitorar, filtrar ou analisar o conteúdo dos pacotes de dados, respeitado o disposto neste artigo". A iniciativa é louvável, mas não cobre todas as situações fáticas supra narradas e, como se sabe, artigos de lei ordinária demandam uma análise constitucional. Além disso, o quão efetivos esses dispositivos serão quando muitos dos agentes envolvidos estão sediados fora do Brasil, ainda não se sabe.

\section{CONSIDERAÇÕES FINAIS}

Como já foi afirmado, não é o objetivo da presente pesquisa ponderar, caso a caso, o direito de acesso à internet e a liberdade de expressão com a liberdade dos agentes econômicos privados, mas sim analisar o poder daqueles que estão no topo da hierarquia física da rede mundial de computadores ou no domínio dos principais sites e softwares.

Assim, conclui-se que há agentes privados que conseguem censurar a internet e que aqueles com maior capacidade de controle são seus verdadeiros donos. Possuir o poder de censurar não significa que esses agentes o exerçam de fato, mas quando eles o fazem, a democracia perde e o direito de acesso à internet também perde.

Chega-se também à constatação de que a internet não é puramente virtual: ela é real. É uma intrincada rede de tubos que formam uma estrutura quase

\footnotetext{
${ }^{23} \mathrm{O}$ exemplo de São Francisco não é perfeito, já que os oficias do BART são agentes públicos, mas o que importa é que o projeto de lei visa a impedir que as empresas de telefonia e internet, que são privadas, possam interromper o acesso sem ordem judicial.
} 
orgânica, conectando prédios ao redor de todo o mundo. Ela nos liga fisicamente mais do que podemos imaginar.

Essa estrutura é tão impressionante que as pessoas esquecem ou não sabem que a rede mundial de computadores foi e ainda é feita à mão. Muitos tiveram que trabalhar fisicamente, passando cabos nas ruas, nos oceanos ou por baixo da terra, para que esse fenomenal sistema pudesse existir.

Por outro lado, cabos sozinhos não formam ideias. A internet é uma rede viva, abastecida por todos os seus usuários. Sem eles, ela morreria, e não seria diferente de uma biblioteca na tela do computador: cheia de informações valiosas, mas estática no tempo e surda para a opinião do leitor. Garante-se o direito de acesso à internet quando se garante o direito de acesso à estrutura física e ao conteúdo de uma internet livre, democrática e plural.

\section{REFERÊNCIAS}

ACUSADA de monopólio, Microsoft libera código de principais softwares. Disponível em: <http://g1.globo.com/Noticias/Tecnologia/0,,MUL3086416174,00-ACUSADA+DE+MONOPOLIO+MICROSOFT+LIBERA+CODIGO +DE+PRINCIPAIS+SOFTWARES.html>. Acesso em: 7 out. 2012.

\section{ADLER, B. Legislature approves Bill requiring court order to shut down} cell phone service. Disponível em: <http://www.capradio.org/176431>. Acesso em: 9 out. 2012.

BALDI, V. Ideologia 2.0: entre memória exteriorizada e exploração digital.

BANGLADESH internet down after submarine cable cut. Disponível em: $<$ http://www.channelnewsasia.com/stories/afp_asiapacific/view/1206158/1/. html>. Acesso em: 4 out. 2012.

BELL, MICHAEL et. al. Apparatus and methods for enforcement of policies upon a wireless device. United States Patent and Trademark Office. Disponível em: $<$ http://patft.uspto.gov/netacgi/nph-Parser?Sect1=PTO2\&Sect2=HITOFF \& $\mathrm{u}=\% 2$ Fnetahtml $\% 2$ FPTO $\% 2$ Fsearch-adv.htm $\& \mathrm{r}=36 \& \mathrm{p}=1 \& \mathrm{f}=\mathrm{G} \& \mathrm{l}=50 \& \mathrm{~d}=\mathrm{PTX}$ $\mathrm{T} \& \mathrm{~S} 1=(20120828 . \mathrm{PD} .+\mathrm{AND}+$ Apple.ASNM. $) \& \mathrm{OS}=\mathrm{ISD} / 20120828+\mathrm{AND}+\mathrm{AN} /$ Apple \&RS $=($ ISD/20120828+AND+AN/Apple $)>$. Acesso em: 8 out. 2012.

BERG, D. VD. How the 'Net works: an introduction to peering and transit. Disponível em: $<$ http://arstechnica.com/guides/other/peering-and-transit.ars/4>. Acesso em: 4 out. 2012. 
BLUM, A. Tubes: a journey to the center of the internet. Kindle, 2012.

BRIGHT, P. Internet Explorer 10 almost doubles its users thanks to Windows 7 release. Disponível em: $<$ http://arstechnica.com/informationtechnology/2013/04/internet-explorer-10-almost-doubles-its-users-thankstowindows-7-release/>. Acesso em: 6 abr. 2013.

DAVIS, A. Amazon passes Google as top destination for Shopping Research [Report]. Disponível em: <http://searchenginewatch.com/article/2196747/ Amazon-Passes-Google-as-Top-Destination-for-Shopping-Research-Report>. Acesso em: 5 out. 2012.

DEIBERT, R. et al. Access denied: the practice and policy of global internet filtering. Cambridge; Massachusetts: The MIT Press, 2008.

DESTRO, G. Microsoft já vendeu 60 milhões de unidades do Windows 8. Disponível em: <http://www.noteshared.com/2013/01/microsoft-ja-vendeu-60milhoes-de.html>. Acesso em: 6 abr. 2013.

FIVEASH, K. UK ISPs crippled by undersea cable snap. Disponível em: $<$ http://www.theregister.co.uk/2012/08/28/cut_underseas_cable_cripples_ networks $>$. Acesso em: 4 out. 2012.

FOWLER, G. A. Facebook: one billion and counting. Disponível em: $<$ http:// online.wsj.com/article/SB10000872396390443635404578036164027386112. html>. Acesso em: 5 out. 2012.

GUADAMUZ, A. Networks, complexity and internet regulation: Scale-Free Law. Cheltenham: Edward Elgar, 2011.

HACKER group posts names of BART site subscribers. Disponível em: <http:// www.msnbc.msn.com/id/44139412/ns/technology_and_science-security/t/ hacker-group-posts-names-bart-site-subscribers>. Acesso em: 9 out. 2012.

KABWEZA, L. S. M. East Africa undersea cable outage enters third week. Disponível em: <http:/www.techzim.co.zw/2012/03/east-africa-underseacable-outage-enters-third-week>. Acesso em: 4 out. 2012.

KUHN, E. Google unveils top political searches of 2009. Disponível em: $<$ http://politicalticker.blogs.cnn.com/2009/12/18/google-unveils-top-politicalsearches-of-2009>. Acesso em: 5 out. 2012. 
LESSIG, L. Code 2.0. Soho Books, 2010.

LONG Road From Cuba: Manny Medina, CEO of Terremark (Part 4).

Disponível em: $<$ http://www.sramanamitra.com/2009/10/31/long-road-fromcuba-manny-medina-ceo-of-terremark-part-4>. Acesso em: 8 out. 2012.

MacKINNON, R. Consent of the Networked: the worldwide struggle for internet freedom. Kindle ed. 2012.

MARKOFF, J. Internet traffic begins to Bypass the U.S. Disponível em: $<$ http://www.nytimes.com/2008/08/30/business/30pipes.html $>$. Acesso em: 3 out. 2012.

MENDES, G. F.; COELHO, I. M.; BRANCO, P. G. G. Curso de Direito Constitucional. 2. ed. São Paulo: Saraiva, 2008.

MOROZOV, E. The net delusion: the dark side of internet freedom. New York: Public Affairs, 2011.

NASCIMENTO, B. L. C. do. Liberdade de expressão, honra e privacidade na internet: a evolução de um conflito entre direitos fundamentais. Kindle, 2011.

NOVAIS, J. R. Direitos fundamentais: trunfos contra a maioria. Coimbra: Coimbra, 2006.

PARFITT, T. Georgian woman cuts off web access to whole of Armenia. Disponível em: <http://www.guardian.co.uk/world/2011/apr/06/georgianwoman-cuts-web-access $>$. Acesso em: 8 out. 2012.

PARISER, E. The filter bubble: what the internet is hiding from you. New York: The Penguin Press, 2011.

POLICE shut down San Francisco transit station after protests. Disponível em: $<$ http://www.msnbc.msn.com/id/44153343>. Acesso em: 9 out. 2012.

RJ proíbe uso de celular nas agências bancárias. Disponível em: <http://www. conjur.com.br/2011-abr-07/estado-rio-janeiro-proibe-uso-celular-agenciasbancarias>. Acesso em: 9 out. 2012.

ROSEMAN, D. The digital divide and the competitive behaviour of Internet 
backbone providers: Part 1 - issues and arguments. Info. v. 5, n. 5, p. 25-37, 2003.

SCHNEIDER, J. Facebook Investor IPO Lawsuits Sent to New York Judge. Disponível em: <http://www.bloomberg.com/news/2012-10-05/facebookinvestor-ipo-lawsuits-sent-to-new-york-judge.html>. Acesso em: 5 out 2012.

SEVERED cables disrupt internet. Disponível em: $<$ http://news.bbc.co.uk/2/hi/ technology/7218008.stm>. Acesso em: 4 out. 2012.

TERREMARK. Fact Sheet: NAP do Brasil. Disponível em: <http://www. terremark.com/uploadedFiles/Technology_Platform/Datacenters/South_ America/TMRK_NAPdoBrasil_Gatefold_02_English_Screen.pdf $>$. Acesso em: 3 out. 2012.

UNITED States v. Microsoft Corporation. Antitrust case filings. The United States Department of Justice. Disponível em: < http://www.justice.gov/atr/cases/ ms_index.htm>.Acesso em: 7 out. 2012.

VAIDHYANATHAN, S. The googlization of everything: and why we should worry. California: University of California Press.

WINDOWS 8 será lançado dia 25 de outubro. Disponível em: <http:// tecnologia.uol.com.br/noticias/redacao/2012/09/17/microsoft-oficializa-datade-lancamento-do-windows-8.htm>. Acesso em: 5 out. 2012.

WU, T. The Master Switch: the rise and fall of information empires. New York: Vintage Books, 2011.

\section{ZAIN, A. A. Cable damage hits one million internet users in UAE.}

Disponível em: <http://www.khaleejtimes.com/DisplayArticleNew. asp? section $=$ theuae $\&$ xfile $=$ data/theuae $/ 2008 /$ february $/$ theuae_february $121 . x m l$ >. Acesso em: 4 out. 2012. 


\title{
INFORMATION EMPERORS: POWER AND CENSORSHIP ON THE INTERNET
}

\begin{abstract}
The purpose of this research is to analyze the extent to which, given the decentralized and network structure of the internet, it is possible to say that it has agents who are able to control the flow of information in it. The authors intend to demonstrate that the worldwide web is not free from owners and their owners are those who have power to intervene in the physical functioning of the system or data stream. In today's world, these would be Apple, Amazon, Facebook, Google, Microsoft and backbone operators.
\end{abstract}

KEYWORDS: Internet civil framework; Silencing agents; Restriction to the Fundamental Right of Freedom of Expression.

\section{IMPERADORES DE LA INFORMACIÓN: PODER Y CENSURA EN INTERNET}

RESUMEN: El objetivo de esta investigación ha sido analizar hasta que punto, dada la estructura descentralizada y la red de internet, es posible decir que la internet tiene agentes capaces de controlar la circulación de informaciones en la misma. Se ha pretendido demostrar que la red mundial de ordenadores no es libre de dueños y que sus propietarios son aquellos que tienen poder de injerencia sobre el funcionamiento físico del sistema o sobre el flujo de datos. En el mundo actual, ellos serían la APPLE, la AMAZON, el FACEBOOK, el GOOGLE, la MICROSOFT y los operadores de BACKBONE.

PALABRAS CLAVE: Marco civil de la internet; Agentes silenciadores; Restricción al Derecho Fundamental de Libertad de Expresión. 